\title{
Twitter Fiction: A New Creative Literary Landscape
}

\author{
Laila Al Sharaqi \\ Department of European Languages and Literature, College of Arts and Humanities, King Abdulaziz University, \\ Jeddah, Saudi Arabia \\ E-mail: laila.alsharqi@gmail.com \\ Irum Abbasi (Corresponding author) \\ Department of Psychology, San Jose State University, San Jose, CA, United States \\ E-mail: irum.abbasi@gmail.com
}

Doi:10.7575/aiac.alls.v.7n.4p.16

URL: http://dx.doi.org/10.7575/aiac.alls.v.7n.4p.16
Received: 03/02/2016

Accepted: 21/04/2016

\begin{abstract}
Twitter, synonymous with social networking, has become a successful social platform for the exchange of ideas, news, and information. It has also emerged as an experimental platform through which users explore creative realms of poetic and narrative content, albeit in 140 characters. The real-time tweets are fundamentally unique and increasingly sophisticated. The attention deficit generation of the fast-paced contemporary world has little time on its hands for extended discourse. Brief stories have been told throughout human history, however, the popularity of short stories skyrocketed with the advent of digital story telling. Twitter has now become a frontier medium that allows a unique mode of digital storytelling that facilitates creative literary experimentation. Twitter offers a unique freedom to writers insofar as a tweet can be an entire bite-sized story or even a snapshot of a story that requires readers' active imagination to complete. Twitter fiction signifies stylistic word economy, compactness, symbolic structure, and implied narrative. Fragmentariness of the story is a marker of Twitter fiction. The proponents of Twitter fiction enjoy the originality, freedom, and diversity of perspectives offered by the Twitter fiction. Critics, however, argue that the mandated 140 character limitation stunts story development and strangulates creativity. This paper examines Twitter fiction and proposes that limited characters stories are the evolutionary answer to the reduced attention span of the tech-savvy generation.
\end{abstract}

Keywords: twitterature, fiction, brevity, literary art

\section{Twitter Fiction: A New Creative Literary Landscape}

The phenomenal growth of social media in the twenty-first century owes itself to the ubiquitous presence of the Internet and the platform it offers to keep users engaged and entertained for hours on end. One such platform is Twitter, originally launched in 2006 to connect small groups through a restricted 140 characters short message service (SMS). Once in the public domain, Twitter's popularity knew no bounds, spreading to the mainstream and becoming one of the major social networking sites. Twitter.com (2015) boasted 500 million tweets per day with 314 million active users, $80 \%$ of whom use mobile devices to access Twitter on the go. Twitter users stay updated with the most recent news or gossip directly from their phones during commercial breaks and even while waiting at the stoplights. Twitter supports 35 languages with $77 \%$ of its users residing outside the US; hence, Twitter has transcended cultural boundaries. The phenomenal popularity of Twitter is based on two user behaviors: those who follow others and those who have followers (Rudin, 2011). Depending on the person using Twitter, it can be a place to chat or share news and information or even eavesdrop on celebrities (Kellogg, 2012). Twitter has also enhanced literary writing and opened new horizons for authors by mixing classic and modern writing styles. This paper examines Twitter fiction-stories told in 140 characters or less - and discusses how literary art is redefined in the digital age in a manner that resonates with readers with little time to spare or with short attention spans.

\section{Twitter Fiction}

Is creativity restricted by a limited character count? Is it possible that the next great novel or poem may consist of a collection of tweets? Can readers actively take part in the development of a story? These questions can be answered by reviewing the stories that currently abound the Internet. Historically, the credit for writing the shortest possible literary masterpiece harkens back to Ernest Hemingway, who according to legend-whether archetypal or not - won a bet when he completed a story in six words: "For Sale: baby shoes, never worn." This story became a prototype for the stories that surfaced on the literary ocean as a separate genre called short-short story. After the advent of the computer and its ubiquity, writers focused on new mediums (blogs, online magazines, etc.) to tell a broad range of stories about human experiences. However, all of those platforms were dwarfed by the popularity of Twitter fiction. The idea of limiting fictional writing to character count was not welcomed at first. However, writers are now warming up to the popularity of shrunk literature and consider fiction to have undergone a natural metamorphosis. For example, Kewin (n.d.) 
considers Twitter to be an invaluable resource for writers, and Franklin (2014) claims that Twitter promotes an increasingly sophisticated type of literary performance art.

Contemporary writers are ambitiously flexing their creative muscles to produce remarkable stories in Twitter-supported languages either through a single tweet or multiple tweet installments. This form of interactive literary performance art was unheard of before writers began telling stories through tweets rather than just updating news and information. Writers are also benefitting from the short-form content by marrying character-count restrictions and network effects to crowd-source stories (Rudin, 2011). This union gives writers the freedom to experiment with form and disseminate their work directly to their readers. Readers, in turn, comment on the story and share it with other users through re-tweets, which further increases readership. Authors can choose to either maintain and extend the original storyline, or use readers' input to add new perspectives and twists to the story. Follow-up tweets may portray a sequence of interconnected scenes or a twist on the original tweet, which keeps readers anxiously hooked for further developments. Franklin (2014) claims that Twitter's unpredictability creates an inherent suspense among readers, who must wait for new tweet installments to arrive. It would have been hard for readers and writers to collect all the stories and sequence them; however, an external website called "Storify" assembles and sequences the Twitter stories and their corresponding follow-up tweets in a chronological manner.

Twitter provides bite-sized stories that appeal to the growing generation of readers with "mite-sized attention span" (Rudin, 2011). Notwithstanding the tweet's consumption at a glance, Twitter fiction is deceptively complex. Santulli (n.d.) claims that some Twitter stories are easy to grasp while others conceal entire mythos behind their simplistic words. Readers perceive the purpose of the story based on their own experiences, not unlike what happens when subjects are asked to respond to the Rorschach cards, which are used in psycho-social experiments. The subjective interpretations of twitter stories are equally evocative and telling (Santulli, n.d.). Successful Twitter stories are impressionistic such that readers must catch the key moment and leave with a take-home message that keeps them engaged long after the story is completed. A characteristic feature of Twitter fiction is the epiphanic moment the reader experiences when the purpose of the story becomes apparent and suddenly its entire meaning dawns on the reader (Santulli, n.d.). Achieving a satisfying story arc in 140 characters is challenging; the trick, however, is to leave much of the story out and let the readers fill the blanks (Kewin, n.d.). These trimmed to the core stories rely on puns, alliterations, acronyms, contractions, and rhythms. Akin to a beam of laser light, Twitter stories must stay sharply focused on the topic at hand with artistic brevity, avoiding digression, extraneous descriptions, and iterations. Moreover, authors must be cognizant of each keystroke and use it with utmost prudence for maximum utility. This practice makes writers adept at filtering unnecessary information. Sometimes authors deliberately add typos to imply an underlying theme.

Literary presence is revitalized in contemporary times through Twitter fiction, nevertheless, some recent literary critics condemn Twitter and allege it to be the main cause of death for poetry in the 21 st century (Santulli, n.d.). Other novelists allege that the modern novel is frivolous and acts as a lightweight accessory written for lightweight thinkers (Penny, 2014). Twitter fiction is considered an incomplete piece of art by traditional standards because it cannot incorporate all five basic traditional elements of a story: the setting, characters, plot, conflict, and resolution. The 140 character limitation renders scene-setting or preamble unnecessary in Twitter fiction (Kewin, n.d.). Patea (2012) terms post modern short stories as plot less anti-stories. There is a fundamental difference between the experience a reader undergoes when reading Twitter fiction as opposed to an immersive fiction that requires deep engagement (Frankin, 2014). The idea of Twitter fiction appears superficial to many and contrary to the established norms that dominate most literary magazines that publish stories and short fiction (Santulli, n.d.). However, the two forms may be proportional based on the time taken to write and read. For example, a great Twitter fiction piece can be written in fifteen minutes and read in thirty seconds; whereas, a great traditional story can be written in about fifteen days, but may take thirty minutes to read. Thus, it balances out the effort for both writing and reading (Santulli, n.d.). Indeed, the popularity of Twitter has to do with the brevity of tweets that resonate with the one byte and go culture of the modern age, and also with the ease and fun offered by writing brief stories instead of painstakingly polishing a fifteen-page story (Santulli,n.d.).

Apparently, many writers are attracted primarily by Twitter's casual immediacy, while others are galvanized by the possibility of creating ambitious works that are fundamentally different from printed literature (Franklin, 2014). Teju Cole, the Nigerian-American writer, gained phenomenal popularity when he converted his Twitter feed into a short story template (Penny, 2014). He sifted through Nigerian newspapers for stories about especially resonant crimes to share in his single tweets (Franklin, 2014). Other renowned and best-selling authors such as Rick Moody, Jennifer Egan, and David Mitchell also started sharing their original work through micro-serialized tweets. Interestingly, two University of Chicago students, Alexander Aciman and Emmett Rensin, collaborated to share the essence of eighty of the greatest literary classics of Western literature in their book, "Twitterature." They used 2800 characters (up to 20 tweets) to tell each story. Aciman and Rensin used acronyms to complete their thoughts within the character limit and even provided a glossary of the terms they used for an easy reference. Reading "Twitterature" may cause some readers to experience moments of inspired hilarity. Nevertheless, Shakespeare, John Milton, Jane Austen, Charles Dickens, and other literary figures may be turning in their graves to read the mimic-laden and often offensive content that refers to their classical literature.

Globally, technology has dramatically changed the ways people write and disseminate their work. Computers, smartphones, and other gadgets have revolutionized interactions between the consumer and the retailer such that more 
and more publishing, selling, buying, and reading happen digitally. Therefore, Twitter fiction has varied goals; it can be used as a marketing vehicle that can take established authors to new heights or even catapult unrecognized authors into the spotlight (Rudin, 2011). Twitter fiction writers can choose to publish their stories individually with an appropriate "hashtag" (\#). Many magazines and Twitter work together to facilitate and promote Twitter fiction. Twitter officially introduced a "Twitter Fiction Festival" in October 2012 as a virtual storytelling celebration on Twitter itself. Later, the festival was sponsored and hosted by Penguin Random House and the Association of American Publishers in collaboration with Twitter. Certain magazines are dedicated exclusively to Twitter fiction such as Nanoism (literary fiction), 7 x 20, escarp, Trapeze, Outshine, Thaumatrope (for genre fiction; fantasy, horror) PicFic (stories based on pictorial prompts), electric literature, etc.

The slogan of the Twitter Fiction Festival is "Twitter is where the world tells its stories all day, every day. " Examples of some of the popular works are below.

"I opened the door to our flat and you were standing there, cleaver raised. Somehow you'd found out about the photos. My jaw hit the floor.”(Ian Rankin)

"You know what Mr Grey?" she said smiling. "I'd rather go home, have a cup of tea and watch Corrie". She lived happily ever after." (Victoria Wright)

"His 1st book was out. He was famous. 'Excuse me?' He poised his pen. She asked him to move. He was in the authors only section." (Shubha Menon).

Novelist Elliott Holt tweeted a murder mystery through the perspectives of three different witnesses.

"On November 28 at 10:13 pm EST a woman identified as Miranda Brown, 44, of Brooklyn, fell to her death from the roof of a Manhattan hotel.

Investigators are trying to determine whether Ms. Brown's death was an accident or if, as some speculate, she was pushed off that roof.

At the time of her death, Ms. Brown was at a party. No one witnessed her fall, but three guests were tweeting from the party all evening.

None of the tweeting guests appear to have known Ms. Brown, but all observed her at various times in the 2 hours leading up to her death.

In an effort to reconstruct the night's events, investigators are analyzing the twitter feeds of those three party guests.

The 3 tweeting guests were:

1) @MargotBurnham, 31, a public relations executive whose firm was hosting the party at which Ms. Brown died.

2) @SimonSmithMilla, 44, of London, who was on the guest list because as he put it, "he knows people."

And 3)@ElsaJohanssen, 26, a self-described "Swedish fashion designer" though she is an American citizen who was born in San Francisco.

What follows, in chronological order, are all the tweets sent from that party, which began at 7:30 pm EST...

...and concluded when police arrived on the scene at 10:17 pm EST." Was Ms. Brown's death a \#homicide, a \#suicide, or an \#accident?

You decide. Read the evidence.

Then tweet your verdict (tonight or tomorrow) using the appropriate hashtag: (\#homicide \#suicide or \#accident) \& \#twitterfiction" 


\section{Conclusion}

Tweeting is a part of the new lifestyle of the twenty-first century generation. With the introduction of Twitter fiction, Twitter has gained a new momentum and increased in popularity. Twitter encourages a diversified readership and interactive storytelling through its revolutionary platform. Twitter fiction is antagonistic to the traditional narrative; it is unconventional and not plot driven. Due to the limited character count, paramount importance is given to frugal word usage. The apparent popularity of Twitter fiction has to do with the ease and fun attached to writing and reading a piece of fictional art on Twitter. Twitter promotes brief stories that can be gobbled up in a glance while also creating new audiences who addictively snack on them. Traditional standards of storytelling have changed with Twitter fiction in that now a masterpiece can be as small as a bite-sized story written by an author in less than 15 minutes and tweeted on Twitter through a hashtag. Classic literature may always dwarf Twitter fiction on any given day. Twitter fiction is not here to replace classic literature. Twitter fiction just provides writers with an opportunity to write their stories and share them with others without having to spend a fortune on publishing, promotion, and advertisement. If the story leaves an impression with the readers, it will bounce from one Twitter account to the other through re-tweets. Happy writing ...

\section{References}

Aciman, A., \& Rensin, E. (2009). Twitterature: The world's greatest books in twenty tweets or less. New York, NY: Penguin Books

Franklin, R. (2014). Character development. Foreign Policy, (209), 104.

Kellogg, C. (2012). The Twitter fiction festival: Making the most of 140 characters.

Retrieved from http:/articles.latimes.com/2012/nov/30/entertainment/la-et-jc-twitter-fiction-festival-making-the-mostof-140-characters-20121129

Kewin, S. (n.d.). Twitter fiction. Really! Daily Writing Tips. Retrieved from http://www.dailywritingtips.com/twitterfiction-really-2/

Penny, L. (2014). The great English novel is dead. Long live the unruly, upstart fiction that's flourishing online. New Statesman, 143, 19-52.

Rudin, M. (2011). From Hemingway to Twitterature: The short and shorter of it. Journal of Electronic Publishing, 14(2), 1-8. doi:10.3998/3336451.0014.213

Santulli, A. (n.d.). Consider twitter fiction. The review review. Retrieved from http://www.thereviewreview.net/publishing-tips/consider-twitter-fiction 